\title{
Acanthaster planci invasions: applying biosecurity practices to manage a native boom and bust coral pest in Australia
}

\author{
Jessica Hoey ${ }^{1, *}$, Marnie L. Campbell ${ }^{2}$, Chad L. Hewitt ${ }^{3}$, Brendan Gould ${ }^{4}$ and Rosemary Bird ${ }^{4}$ \\ ${ }^{1}$ Great Barrier Reef Marine Park Authority, PO Box 1379, Townsville, Queensland 4810, Australia \\ ${ }^{2}$ Environmental Research Institute, University of Waikato, Hamilton, New Zealand \\ ${ }^{3}$ School of Science, University of Waikato, Hamilton, New Zealand \\ ${ }^{4}$ Ministry for Primary Industries, Wellington, New Zealand \\ E-mail addresses: jessica.hoey@gbrmpa.gov.au(JH), marnie.campbell@waikato.ac.nz (MLC), chewitt@waikato.ac.nz (CLH), \\ brendan.gould@mpi.govt.nz (BG),rosemary.bird@mpi.govt.nz (RB) \\ *Corresponding author
}

Received: 30 May 2016 / Accepted: 16 July 2016 / Published online: 25 July 2016

Handling editor: Vadim Panov

\begin{abstract}
Coral reef systems are in global decline. In Australia, much of this decline has been attributable to cyclic outbreaks (every $\sim 17$ years) of the coral-feeding crown-of-thorns seastar. While a native species, when in large enough densities the seastar acts like an invasive pest. Since 2012 the Australian government has invested significantly in a targeted control program using lethal injection. While this program is effective for individual reefs, it is not a complete strategy for the entire Great Barrier Reef ( 2,500 reefs). In order to find a longer-term solution to the problem, in 2015, the lead author travelled to New Zealand, the United States, and Canada under a Churchill Fellowship to understand successful aquatic integrated pest management strategies and their potential application to the Great Barrier Reef. Meetings and workshops were convened with experts who specialise in risk assessment, categorisation, and management of aquatic invasive species. The experts comprised academics, applied scientists, policy makers, and a not for profit community based invasive species council. Bioinvasion management and prioritisation of management effort using risk-based frameworks were reviewed for application to the crown-of-thorns seastar. This viewpoint is novel in its approach of applying invasive species tools and perspectives to a non-invasive, native marine pest. Early detection and rapid response is key to preventing the transition of the seastar from natural densities to outbreak densities. However given the seastar is a native species already established, when in outbreak mode a multifaceted post-border management approach is essential. Private support funding models, that bridge conservation and tourism/philanthropy have proved successful in New Zealand to supplement government funded marine reserve management - this is an approach which should be explored by Australia to help manage the seastar. Dedicated support and commitment is needed to break the issue-attention cycle. On the Great Barrier Reef, a dedicated biosecurity approach should be used to maintain the seastar at natural densities, increase the time between outbreaks, protect coral cover and increase resilience of the system.
\end{abstract}

Key words: seastar, pest management, issue-attention cycle, early detection, rapid response

\section{Introduction}

Acanthaster planci (Linnaeus, 1758), the crown-ofthorns seastar, are voracious, opportunistic carnivores that typically consume sessile invertebrates, particularly hard corals, and carrion. A. planci has exhibited long-term boom-bust population cycles to devastating effect in the Indo-Pacific, specifically threatening the Great Barrier Reef (e.g., Uthicke et al. 2009; Baird et al. 2013). Acanthaster planci is now identified as a species complex, with four genetically distinct species (Vogler et al. 2008) and is distributed globally throughout the Indo-Pacific (Moran 1988a, b), making them native to Australian waters. A recent extension of this seastar has also been reported in the Galápagos Islands (I. Keith, pers. comm.).

On the Great Barrier Reef there have been four documented A. planci outbreaks since the 1960's, each spaced $\sim 17$ years apart (Pratchett et al. 2014). During these outbreaks natural densities increase to a point resulting in "plagues" of the seastar consuming coral faster than it can grow. Broad awareness of 
A. planci outbreaks on the Great Barrier Reef first occurred in the 1960's, probably due to development of outboard motors and the ready availability of SCUBA diving at the time, which together increased access to the reef. While geological records suggest that outbreaks of $A$. planci may have naturally occurred on the reef before this time (Walbran et al. 1992) this evidence has been disputed by others (Keesing et al. 1992). Debate is still occurring over what triggers these boom periods (e.g., Brodie et al. 2005; Vogler et al. 2008; Fabricius et al. 2010) and whether the Great Barrier Reef can survive further A. planci outbreaks (De'ath et al. 2012) given the cumulative effects that it is exposed to already (such as increased storm frequency; coral bleaching and diseases; dredging; nutrient, sediment and pollutant run-off; e.g., Bellwood et al. 2004; Fabricius et al. 2005). Irrespective of the trigger for the outbreaks and additional threats, A. planci pose an immediate and significant threat to coral cover and ecosystem function. This presents serious issues: environmental, cultural, social and economic because coral reefs provide food, habitat, structure and resources for the ecosystem and humans. Viewed as a single stressor, A. planci outbreaks are the second largest cause of coral loss on the Great Barrier Reef and pose an immediate risk to coral cover and values that rely on healthy coral. Viewed as a cumulative stressor, (and one of the few with a suite of options for management intervention), outbreaks pose a significant direct risk to the process of recovery at an ecosystem scale.

In 2010, the beginning of the current $A$. planci outbreak, a renewed round of government investment for research and intervention was commenced (GBRMPA 2014a). The Australian government invested significantly in a targeted control program, which continues today, using lethal injection of a bile salt solution (GBRMPA 2014a). While this program is effective for adults on individual reefs, it is not a viable strategy for the entire GBR $(\sim 2,500$ reefs). A longer-term, more integrated management strategy is needed to address recurrent outbreaks and protect coral cover, diversity and ecological function. This manuscript examines the $A$. planci epidemic from an invasive species perspective. Pests can be defined as "any organism having, or with the potential to have, an adverse economic, environmental or social impact" (Natural Resource Management Ministerial Council 2007). While it may seem misplaced to apply invasive species tools to a native species, A. planci have all the hallmarks of a pest (e.g., boom and bust life cycle, high fecundity, omnivorous diet). Therefore integrated [native] pest management is an approach that should be explored within a marine system in Australia.

\section{Methods}

The lead author (JH) successfully sought an Australian Churchill Fellowship to better understand successful pest management strategies and how they could be applied to crown-of-thorns seastar outbreaks on the Great Barrier Reef. This entailed travel to three countries (New Zealand, U.S.A, and Canada) to meet with researchers, community organisations and pest management experts with the support of the Churchill Trust and from her employer - the Great Barrier Reef Marine Park Authority.

As a result of this Fellowship, the collaborating authors participated in a series of meetings and workshops to identify a set of biosecurity styled approaches that could be useful to developing an integrated [native] pest management program, for both non-native and native species. Expert elicitation techniques were used by the primary author to define the problem, identify the experts and independently meet with individual experts (individual interview). On occasions, facilitated discussions with a group of experts (open forum interviews) was also utilised. Before interview commencement, the issue and scope of the A. planci problem on the Great Barrier Reef was described; this ensured that recall bias was addressed. A general expert elicitation process was followed, with five broad and accepted steps (Martin et al. 2012) being implemented: i) determine information "use" decisions, ii) identify the type of information required, iii) identify the interview type, iv) undertake and complete interview process, and v) translate expert evidence into an integrated [native] pest management framework for the Great Barrier Reef.

\section{Results and discussion}

Six biosecurity styled approaches are detailed below and discussed in the context of their application to crown-of-thorns seastar management on the Great Barrier Reef:

\section{Establishing and maintaining a knowledge base}

A common issue for biosecurity managers is a dearth of knowledge concerning potential invading species' life-histories that might inform management opportunities, probable impacts to value attributes, and mechanisms of dispersal (e.g., Hewitt et al. 2004; Azmi et al. 2015). One lesson from invasion ecology readily applied to $A$. planci is the understanding of critical stages in life-history to inform cost-effective management actions and determine outbreak triggers (Pratchett et al. 2014). Due to the boom-bust nature of $A$. planci outbreaks, it is also critical to understand 
what conditions support the non-outbreak periodsas this is ultimately the phase we want to keep the Great Barrier Reef in. This "mission-focus" requires a long-term prioritised research strategy to support a broader management framework and achieve the overarching outcome - the protection of coral cover and diversity. This strategic approach would allow the creation of governance structures that set cohesive research priorities and bring partners together to enhance collaboration and maintain directed research to address the most pertinent knowledge gaps.

One phenomenon noted from the previous A. planci outbreaks in Australia is a lack of continued focus inbetween outbreaks, i.e. during the non-outbreak periods. Funding models that respond to events (such as outbreaks) tend to be politically motivated or motivated by the protection of key tourism assets (e.g. Green Island in the 1980's). This type of behaviour exposes the environment to an "IssueAttention-Cycle" where cyclic loss of expertise and momentum occurs once the event ceases to gain public/policy attention and therefore funding support (Downs 1972). An Issue-Attention Cycle within a science funding context as described by Downs (1972) refers to how funding is often driven by crises leading to public outrage and reactive funding due to political interest. Hence, funding often only becomes available when a problem occurs, and once funding is provided, the problem is perceived as being managed, therefore the public and political concern dissipates, leading to a loss of funding, and then the cycle repeats. This type of funding often results in a "band-aid" approach to solutions impeding longer term funding that is required to properly manage the issue pro-actively. If the problem is cyclic, multiple injections of funding over time eventually cost more at the expense of a longer-term integrated approach which deals with the problem more strategically and usually costs less. As a consequence of the current short-injection funding cycle, a dedicated $A$. planci researcher may only experience 1-2 outbreaks in their working life, requiring the researcher to undertake a shift in research focus in order to maintain a viable research career. The research that occurs during these events may therefore result in a focus on short-term response rather than creating long-term understanding and solutions.

\section{Surveillance and detection}

Most effective biosecurity management frameworks have at their core characteristics of prevention, early detection and rapid response. Surveillance differs from monitoring (a latter step in a comprehensive management program) because surveillance targets high risk pathways, species and locations and captures change in relation to a management activity (Hellawell 1991). A pro-active approach that detects a newly arrived pest can enable rapid and early response that are likely to be both less costly and more effective. Appropriately focused surveillance relies on a range of factors including:

1. Clear surveillance and detection objectives (e.g., detection at what density, what spatial scale);

2. Knowledge acquired from past invasions to determine high(er) probability locations and timing of new invasions; and

3. Having the tools, methods, resources (expertise and funding), governance and communication networks in place to ensure the surveillance objectives can be met (e.g., Davidson et al. 2015).

Within an $A$. planci context, conjecture exists that phytoplankton blooms are circumstantially linked to outbreaks (Fabricius et al. 2010). This inference is based upon flood events that lead to increased nutrient runoff, with subsequent increases in phytoplankton blooms and then $A$. planci outbreaks (Brodie et al. 2005; Hutchings et al. 2005). Irrespective of whether or not a trigger can be categorically linked back to nutrient enrichment pulses, added awareness of the 17-year outbreak cycle (Pratchett et al. 2014) should assist surveillance efforts. Intensive monitoring of A. planci at Lizard Island over a period in the 1990s identified a slow build-up of adults, which formed the primary outbreak that occurred in 1996 (Sweatman et al. 1998; Pratchett 2005; Pratchett et al. 2014). Hence, ideally surveillance should be increased within this temporal frame (during the non-outbreak period) and potentially intensified after a trigger, such as a flood event or extensive phytoplankton blooms. Surveillance could target the entire region that may be affected, or if an identified source (or an invasion beach-head) area is known then this would be targeted with sink areas targeted as a back-up.

Targeting known and potential sources of an invasion or outbreak creates an early detection-rapid response model. Within the $A$. planci example, a dedicated surveillance regime would need to have temporal and spatial components. Temporal surveys would need to be designed to target both nonreproductive and the aggregating build up, when starfish begin to aggregate to reproduce in the warmer months. The spatial component targets potential sources and strategically identified sinks. An epidemiological approach that utilises network theory (e.g., Kiss et al. 2006; Youssef et al. 2011) to create hub and spoke models (e.g., Azmi et al. 2015) could be useful for identifying the starting point of 
an outbreak and the subsequent spread both temporally and spatially. The surveillance regime would need to be sensitive enough to detect the pests at an appropriate scale while also at low enough densities, but requires understanding of trade-offs between effort and benefit (e.g., Davidson et al. 2015). Passive surveillance (Campbell et al. 2007) might be a useful tool to detect unwanted species and has been used in Darwin, Australia, to detect the black striped mussel (Willan et al. 2000). This method, while generally having lower sensitivity and specificity, plays a cost effective supporting role to targeted surveillance given its potential for wider geographic coverage and user-friendly collection (e.g., water sampling). Use of evolving technology should be considered. For example, in the Great Lakes, environmental DNA (eDNA) has been effectively used to detect the signature of pests (e.g., Jerde et al. 2011) even at low densities. Therefore, eDNA is a useful tool that can detected a species before it is visually detected by divers. As such, this tool could be useful in detecting the outbreaks before that reach unmanageable levels.

\section{Rapid response}

Marine borders are fluid making prevention and control appear harder than terrestrial systems and closed water bodies (Hewitt et al. 2004, 2009). Once a pest species (native and non-native) is detected, suitable eradication methods need to be employed quickly, with quarantine and buffer zones created to restrict spread (secondary invasions) and further contamination. The epidemiology of the species and potential connectivity between sources and sinks is imperative to manage the containment and spread of a species. Given $A$. planci are native to the Great Barrier Reef, epidemiology could be used to understand the boom and bust cycle of the species and potential origins or initiation points. Coupled with hub and spoke models (e.g., Azmi et al. 2015) that focus on how the species will spread, will provide and idea of where rapid response efforts need to be deployed.

For A. planci, the Great Barrier Reef Marine Park Authority is starting to use risk estimation modelling to formulate a connectivity-based intervention strategy (Hock et al. 2016) which will identify priority source and sink reefs linked by water currents - the transport corridors for the larvae. By using this adaptive intervention approach in combination with prioritisation frameworks (Hewitt et al. 2004), surveillance and control resources can be more strategically directed to address this native pest.

Rapid response requires an established governance system, teams and protocols to enable a coordinated response in accordance with agreed decision frameworks. Additionally, this coordinated response framework then requires ready access to resources for immediate deployment once triggers are met. Any delay in response may result in a lost opportunity to reduce $A$. planci densities to levels that are not reproductively viable and potentially disrupt the outbreak cycle. On the Great Barrier Reef, agreed decision frameworks have improved with each outbreak. However, this has not been formally captured within a policy framework linked to ready resources that can be allocated when the environmental triggers are met (rather than triggered by political or social concern).

\section{Monitoring}

Monitoring activities systematically measure and evaluate the presence/absence or compliance with a threshold over time (Hellawell 1991) and are imperative to inform actions and determine management effectiveness. In New Zealand, regular monitoring is undertaken for a range of pest species to determine presence and indicate spread to new locations (Ministry for Primary Industries: https://www.mpi.govt.nz/ protection-and-response/finding-and-reporting-pests-and-disea ses/surveillance-programmes). Structured monitoring is not always feasible, particularly in locations that are remote, such as the Far Northern Great Barrier Reef in Australia. As such, a suite of monitoring tools are needed that use consistent detection thresholds for the $A$. planci (planktonic, juvenile and adult stages), biological thresholds (e.g. for coral, phytoplankton during the larval phase) and management triggers to enable interoperability and increase certainty around resource needs and management decisions.

At a broad citizen science level, there is growing use of social media and phone applications to provide an early warning system for environmental impacts and bioinvasions (e.g., Eye on the Reef Program GBRMPA; Seastarwasting.org; Pestwatch WA). Responsive structured monitoring is then required to verify the threat and inform response. From 201215 , the largest ever $A$. planci surveillance program was conducted on the Great Barrier Reef by the jointly funded operational arm of the Great Barrier Reef Marine Park Authority and the Queensland Government. Over 8,333 manta tows covering 1,450 kilometres of reef edge, additional timed swims (if outbreak densities from the manta tows were observed), and 2,258 Reef Health Surveys were completed (Field Management Program Annual Report 2015). These underwater surveys recorded coral type, coral health, number of $A$. planci feeding scars, and number of live A. planci. Data collected was geo-spatially referenced and encompassed in a central database. 
While this monitoring was post-incursion (i.e. after A. planci outbreak had established), it implemented a comprehensive and robust monitoring strategy that allowed managing agencies to quickly identify outbreaks, understand which reefs still had preferred coral food for the seastar, or reefs where food was below a critical threshold - and therefore beyond assistance. This type of program should be temporally extended to cover both non-outbreak and outbreak periods to facilitate early detection, monitor effectiveness, adapt response efforts and support prioritised research efforts discussed earlier in this paper.

\section{Communication and preparedness}

New Zealand, the US and British Columbia have well-established public education and management systems for invasive species (e.g., Hewitt et al. 2004, 2009; Ministry of Forestry and Agriculture 2007). Australia has a nationwide management approach to marine biosecurity but we would argue that the national public education and management systems in Australia are lagging behind contemporary countries such as New Zealand, Canada and the USA. The strength of New Zealand's pest management approach is the presence of documented long-term strategies, pro-active action plans, and strong public education. Australia does not have an integrated long-term management strategy for the protection of coral from pressures which include the crown-of-thorns seastar. A. planci are currently managed as a cost of $\sim \$ 2$ million dollars per annum during an outbreak with limited to no dedicated funding allocated in bust cycles. We recognise that $A$. planci is a native pest species that is poorly managed in a pro-active manner. If the seastar were treated like a non-native species, then management would move from a reactive to a pro-active approach, with more efficient public education. These aspects are currently missing from the current management approach. The crux of a successful biosecurity management plan is collaboration and effective communication, which is often promulgated through community preparedness.

Community preparedness relies on planning and testing of prompt and efficient biosecurity response processes at local, state, national and/or international levels. These often occur via hypothetical infection scenarios that aim to create intra and interjurisdictional communication pathways and response coordination. Specific biosecurity exercises aim to heighten community awareness of potential incursions. For example, Exercise Tethys (http://www.daff.gov.au/ animal-plant-health/emergency/exercises/tethys) was a field-based exercise that simulated a multi-state aquatic animal disease outbreak. These types of exercises are common in terrestrial ecosystems for events such as foot and mouth outbreaks (e.g., exercise Minotaur; http://www.daff.gov.au/animal-plant-health/em ergency/exercises/minotaur) and provide an opportunity to test the biosecurity system while raising awareness within the community. Such exercises enable the creation of tested forecast and warning systems.

An A. planci "biosecurity" exercise could be run that creates the opportunity to refine a forecast and early warning system. Specifically, forecast and early warning systems would raise an alarm when conditions are detected that would trigger a threat situation (such as a slow increase in adult $A$. planci densities in the Lizard Island region or high rainfall, leading to phytoplankton blooms). Information about the potential threat is then disseminated to response networks and community within the likely "infected" zone. A response could then be initiated and could range from informing the Minister for the Environment to more tactical objectives such as mobilising community groups to aid lethal injection of $A$. planci. Of importance is having a plan for when a threat is detected and knowing the different mitigation steps that may ensue. For example, avoidance of $A$. planci is not a mitigation step that can be implemented, but transference (allowing different groups to manage the risk, such as co-opting dive operations and a public "protect your patch" network) might be possible. Actions that are more likely to produce favourable risk mitigation outcomes, are risk reduction (by providing funding to the issue outside of incursion events), creating pro-active biosecurity, and developing codes of practice for detection and treatment and more comprehensive reporting by vessels and Reef users.

\section{Funding models}

Traditional pest management is commonly driven by economics, where the investment to prevent and eradicate should usually be less than the generated economic value of the resource(s) being protected. Almost all commercial, social and cultural values of any system are dependent on the integrity of the ecosystem (GBRMPA 2014b). The Great Barrier Reef is valued well beyond its local communities, with strong national and international interests. Although restoration can enhance conservation efforts and should be considered in certain circumstances, it is always a poor second to the preservation of original habitats (Young 2000). A US based review of reef restoration costs estimates the median cost to restore a coral reef from a damaged/depauperate state using biorock was US\$1,290 $\mathrm{m}^{-2}$, or US $\$ 12.9$ million $\mathrm{ha}^{-1}$ (Ferrario et al. 2014). Biorock was 
considered the more advanced alternative (given its surface is more attractive to larvae) than using concrete blocks and bioballs to replace structure following destructive incidents (storms, blast fishing). Analysis of data from two years of the Great Barrier Reef A. planci control program costs, taking into account vessels, divers, fuel and injection chemicals amounted to $\sim \$ 2.3$ million $\mathrm{yr}^{-1}$ for two vessels running concurrently (with a second vessel added to boost culling during the spawning season period). What this delivered, was protection of coral cover on a number of high value reefs with a combined total area of $\sim 3000$ ha. While each square metre of each high value reef was not surveyed and controlled on every visit, 6-8 week re-visitation frequency was maintained by dive crews. This resulted in the maintenance and protection of average coral cover on most reefs above critical thresholds. Averaging the costs across the reef area protected under this scenario for one year equated to $\sim \mathrm{AU} \$ 800 \mathrm{ha}^{-1} \mathrm{yr}^{-1}$ to protect coral cover through coordinated manual control.

Funding for any marine conservation programs, not to mention preventing bioinvasives, can be costly. However, early detection and early prevention will usually be a cheaper alternative to short-term protection of a small number of high-value areas from established pests and/or habitat restoration. Irrespective of clear cost benefit outcomes from early detection and early prevention, society commonly suffers "fiscal pragmatism" which dictates a "do nothing strategy" due to competing priorities and the hesitation to use public funding until scientific evidence can show enough harm is caused and/or public outcry is great enough to warrant action (Hewitt et al. 2009). It is a question of space, time and values. There are usually two main options:

1. acute intervention - planned funding, early detection, early response, which may deliver a scorched earth approach but with a smaller impact footprint;

2. chronic spending - delayed funding, usually aimed at containing impact rather than prevention, longer term investment required, persistent impact, larger impact footprint.

The Marine Ecosystems Team at the Department of Conservation (DoC, NZ) have "thought outside the box" and expanded monitoring and management effectiveness of their 44 marine reserves through strong partnerships with private enterprise. With the help of funding from Air New Zealand (and other partners), DoC are developing a national monitoring framework to gain an understanding of the value of protection and expand the current marine reserve monitoring program using indicator species. Public exposure to the reserves has been significantly increased through Air New Zealand marketing campaigns and social media competitions. The success of this partnership is built on aligned visions-healthy reserves are great tourism destinations. The same could be said for the Great Barrier Reef, which contributes $\$ 6$ billion dollars to the economy annually via tourism and commercial fishing (Deloitte Access Economics 2013).

\section{Conclusion}

The long term prospects for the Great Barrier Reef are of concern without a dedicated long-term framework to specifically target the higher risk, quick return impacts affecting coral cover during A. planci boom periods as well as monitoring and understanding the conditions needed to support bust cycles. Coral cover and associated diversity has declined by $50 \%$ over the past 30 years (De'ath et al. 2012) due to a number of factors with $A$. planci being the second largest cause of coral loss after storms. It has been estimated that if $A$. planci predation had not occurred over the past 30 years then instead of decline, there would have been a net increase in average coral cover (De'ath et al. 2012). Given the crown-of-thorns seastar is a native species, with the highest reproductive capacity of any marine invertebrate (Pratchett et al. 2014) reef-wide eradication is not feasible. Viewed as a cumulative stressor, the current outbreak poses a significant direct risk to the process of recovery at an ecosystem scale. We are fortunate that this cumulative stressor has a suite of management intervention options that can elevate the effects. Here we considered a suite of biosecurity approaches typically utilised for non-native species to determine how they might be applied to develop an "integrated [native] pest management" approach.

While components of some of the concepts described above have already been applied to A. planci outbreaks, the adoption of a holistic framework that incorporates:

1. Identification of triggers and methods to report and respond to these;

2. Reduction of outbreak-positive conditions and disruption of spawning success (e.g., via targeting early response efforts to aggregations preparing to spawn, increasing the distance between adult seastars through the use of pheremone deterrents currently being investigated at the Australian Institute of Marine Science); 

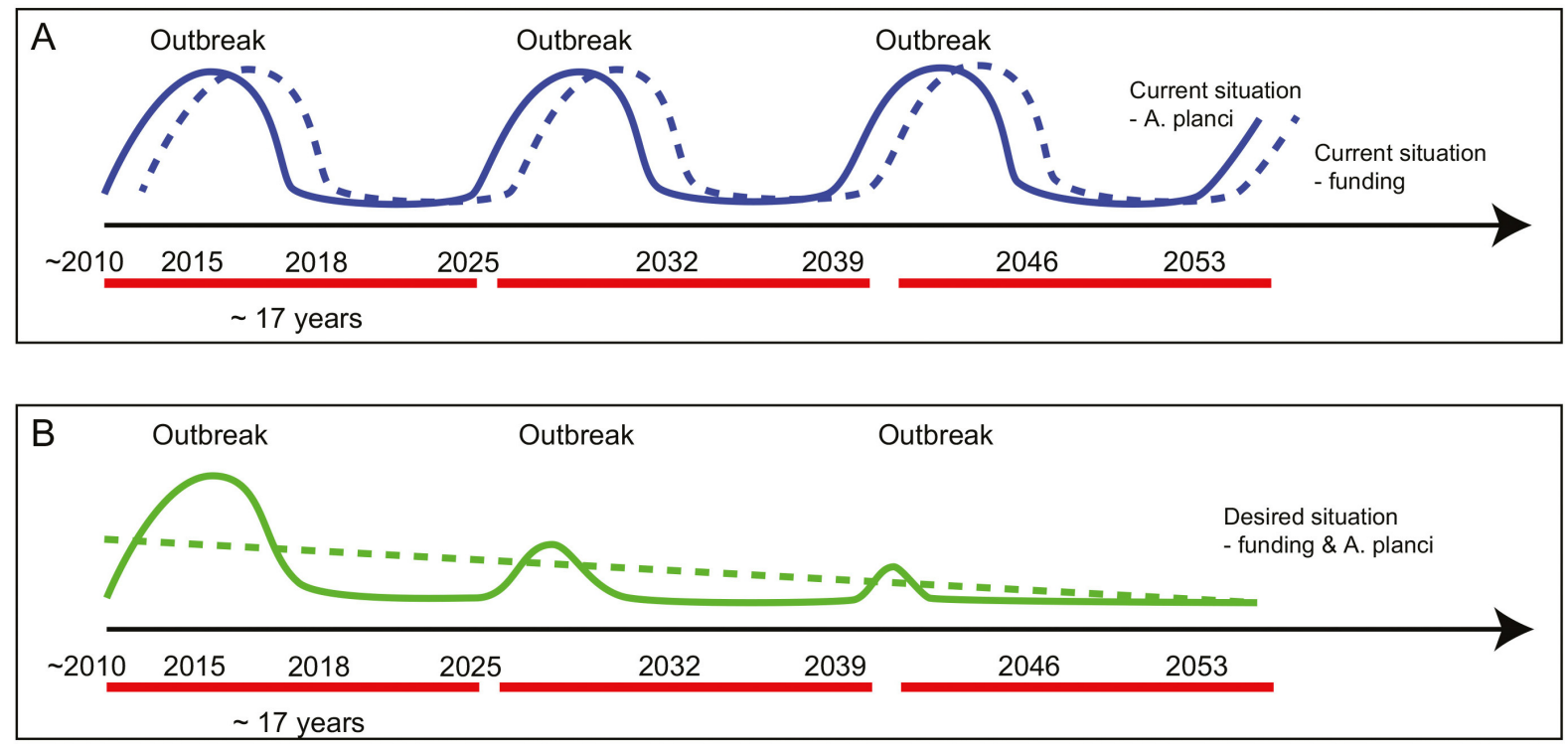

Figure 1. Outbreak conditions (seastar density - solid blue line) and funding response (dashed blue line) under current management strategy (A) and proposed long-term management strategy (B). The current management strategy is reactive resulting in delayed response to outbreaks, a pulse funding response which together may enhance coral loss and decrease available coral recovery times between outbreaks. The desired situation (green lines) creates a biosecurity strategy which maintains a long term focus, decreasing outbreak size and holistically protects coral cover from seastar predation (and other pressures) and ultimately requires reduced funding response over the longer term.

3. Establishment of appropriately tailored surveillance and monitoring, particularly through new passive technology and citizen science initiatives, will enhance the opportunity for early interventions;

4. Mobilisation of rapid response when increases in the threshold of recruits and adults are detected and continuous evaluation to determine the percentage of successful recruits that need to be removed to decrease an outbreak in to the future and spatially;

5. Creation of a long-term strategy to establish governance frameworks and prioritise knowledge gaps will create a mission-led approach to smooth the boom-bust cycle of research and management funding (see Figure 1).

The adoption of a holistic biosecurity model will move Australia (and other countries suffering A. planci outbreaks) to the forefront of strategic A. planci management, contribute significantly to the maintenance and improvement of reef health and provide greater security for reef-dependent industries, cultural connections and community benefits.

\section{Acknowledgements}

JH thanks the Winston Churchill Memorial Trust for financial support to meet with experts on pest management and the generous time and knowledge donated. In particular Sean Cooper, Laura Wakelin and Madeleine McCarroll at the Department of Conservation, Te Papa Atawhai, New Zealand. JH also acknowledges Australian Government funding and efforts to respond to the crown of thorns seastar threat. $\mathrm{MC}$ and $\mathrm{CH}$ acknowledge funding support from the Australian Ministry of Agriculture and Ministry of the Environment, and the Ministry of Primary Industries. The authors acknolwedge and thank Dr Justin McDonald for his constructive review which improved the manuscript.

\section{References}

Azmi F, Hewitt CL, Campbell ML (2015) A hub and spoke network model to analyse the secondary dispersal of introduced marine species in Indonesia. ICES Journal of Marine Science 72: 10691077, http://dx.doi.org/10.1093/icesjms/sul50

Baird AH, Pratchett MS, Hoey AS, Herdiana Y, Campbell SJ (2013). Acanthaster planci is a major cause of coral mortality in Indonesia. Coral Reefs 32: 803-812, http://dx.doi.org/10.1007/s00338013-1025-1

Bellwood DR., Hughes TP, Folke C, Nystrom M (2004) Confronting the coral reef crisis. Nature 429: 827-833, http://dx.doi.org/10. 1038/nature02691

Brodie J, Fabricius K, De'ath G, Okaji K (2005) Are increased nutrient inputs responsible for more outbreaks of crown-ofthorns starfish? An appraisal of the evidence. Marine Pollution Bulletin 51: 266-278, http://dx.doi.org/10.1016/j.marpolbul.2004.10.035 
Campbell ML, Gould B, Hewitt CL (2007) Survey evaluations to assess marine bioinvasions. Marine Pollution Bulletin 55: 360 378, http://dx.doi.org/10.1016/j.marpolbul.2007.01.015

Davidson AD, Hewitt CL, Kashian DR (2015) Understanding ALOR: incorporating the economic cost associated with missing impacts in the design of invasive species management strategies. PloS ONE 10: e0141958, http://dx.doi.org/10.1371/journal.pone.0141958

De'ath G, Fabricius, KE, Sweatman, H, Puotinen M (2012) The 27year decline of coral cover on the Great Barrier Reef and its causes. Proceedings of the National Academy of Sciences 109: 17995-17999, http://dx.doi.org/10.1073/pnas.1208909109

Deloitte Access Economics (2013) Economic Contribution of the Great Barrier Reef, Great Barrier Reef Marine Park Authority, Townsville, pp 1-43

Downs A (1972) Up and down with ecology - the "issue-attention cycle". National Affairs 28: 38-50

Fabricius K, De'ath G, McCook L, Turak E, Williams DM (2005) Changes in algal, coral and fish assemblages along water quality gradients on the inshore Great Barrier Reef. Marine Pollution Bulletin 51: 384-398, http://dx.doi.org/10.1016/j.marpolbul.2004.10.041

Fabricius KE, Okaji K, De'ath G (2010) Three lines of evidence to link outbreaks of the crown-of-thorns seastar Acanthaster planci to the release of larval food limitation. Coral Reefs 29: 593-605, http://dx.doi.org/10.1007/s00338-010-0628-z

Ferrario F, Beck MW, Storlazzi CD, Micheli F, Shepard CC, Airoldi L (2014) The effectiveness of coral reefs for coastal hazard risk reduction and adaptation. Nature Communications 5: 3794, http://dx.doi.org/10.1038/ncomms4794

Field Management Program Annual Report Summary (2014-15) 111, http://library.gbrmpa.gov.au/jspui/handle/1 1017/2983

Great Barrier Reef Marine Park Authority (2014a) Crown-of-thorns starfish control guidelines, GBRMPA, Townsville, pp 1-19

Great Barrier Reef Marine Park Authority (2014b) Great Barrier Reef Outlook Report 2014, GBRMPA, Townsville, pp 1-311

Hellawell JM (1991) Development of a rationale for monitoring. In: Goldsmith FB (ed), Monitoring for Conservation and Ecology. Chapman and Hall, London, pp 1-14, http://dx.doi.org/10.1007/97894-011-3086-8 1

Hewitt CL, Willing J, Bauckham A, Cassidy AM, Jones L, Wotton DM (2004) New Zealand marine biosecurity: delivering outcomes in a fluid environment. New Zealand Journal of Marine and Freshwater Research 38: 429-438, http://dx.doi.org/10.1080/002883 30.2004.9517250

Hewitt CL, Everett RA, Parker N, Campbell ML (2009) Marine Bioinvasion Management: Structural Framework. In: Rilov G, Crooks JA (eds), Biological Invasions in Marine Ecosystems, Springer-Verlag Berlin Heidelberg, pp 327-334

Hock K, Wolff N, Beeden R, Hoey J, Condie S, Anthony K, Possingham H, Mumby P (2016) Controlling range expansion in habitat networks by adaptively targeting source populations. Conservation Biology 30: 856-866, http://dx.doi.org/10.1111/cobi.12665

Hutchings P, Haynes D, Goudkamp K, McCook L (2005) Catchment to Reef: Water quality issues in the Great Barrier Reef region an overview of papers. Marine Pollution Bulletin 51: 3-8, http://dx.doi.org/10.1016/j.marpolbul.2004.11.026

Jerde JL, Mahon AR, Chadderton WL, Lodge DM (2011) "Sightunseen" detection of rare aquatic species using environmental DNA. Conservation Letters 4: 150-157, http://dx.doi.org/10.1111/ j.1755-263X.2010.00158.x

Joint Standing Committee on Conservation/Standing Committee on Fisheries and Aquaculture National Taskforce on the Prevention and Management of Marine Pest Incursions (1999) National Control Plan for the introduced marine pest Northern Pacific Seastar (Asterias amurensis), pp 1-215, https://www.environment. gov.au/resource/joint-sccscfa-national-taskforce-prevention-and-managementmarine-pest-incursions
Keesing JK, Bradbury RH, DeVantier LM, Riddle MJ, De'ath G (1992) Geological evidence for recurring outbreaks of the crownof-thorns starfish: a reassessment from an ecological perspective. Coral Reefs 11: 79-85, http://dx.doi.org/10.1007/BF00357425

Kiss IZ, Green DM, Kao RR (2006) The network of sheep movements within Great Britain: network properties and their implications for infectious disease spread. Journal of the Royal Society Interface 3: 669-677, http:/dx.doi.org/10.1098/rsif.2006.0129

Martin TG, Burgman MA, Fidler F, Kuhnert PM, Low-Choy S, McBride M, Mengersen K (2012) Eliciting expert knowledge in conservation science. Conservation Biology 26: 29-38, http://dx.doi.org/10.1111/j.1523-1739.2011.01806.x

Ministry of Forestry and Agriculture (2007) Didymo Long-Term Management Programme, MAF Biosecurity Information Paper No: 2007/03, pp 1-19

Moran P (1988a) Crown-of-thorns starfish: Questions and Answers. Information Sheet. Australian Institute of Marine Science; Townsville, Queensland. Online reference series, http://epubs.aims. gov.au/bitstream/handle/11068/2193/Moran_Crown-of-thorns-questions\%20and $\% 20$ answers.pdf? sequence $=1$

Moran P (1988b) The Acanthaster phenomenon. Australian Institute of Marine Science Monograph Series 7: 379-480

Natural Resource Management Ministerial Council (2007) Australian Pest Animal Strategy - A national strategy for the management of vertebrate pest animals in Australia, pp 1-25

Pratchett MS (2005) Dynamics of an outbreak population of Acanthaster planci at Lizard Island, northern Great Barrier Reef (1995-1999). Coral Reefs 24: 453-462, http:/dx.doi.org/10.1007/s0 0338-005-0006-4

Pratchett MS, Caballes CF, Rivera-Posada JA, Sweatman HPA (2014) Limits to understanding and managing outbreaks of crown-of-thorns starfish (Acanthaster spp.). Oceanography and Marine Biology an Annual Review 52: 133-200, http://dx.doi.org/ 10.1201/b17143-4

Sweatman H, Bass DK, Cheal AJ, Coleman G, Miller IR, Ninio R, Osborne K, Oxley WG, Ryan DAJ, Thompson AA, Tomkins P (1998) Long-term Monitoring of the Great Barrier Reef. Status Report Number 3. Australian Institute of Marine Science, Townsville

Uthicke S, Schaffelke B, Byrne M (2009) A boom-bust phylum? Ecological and evolutionary consequences of density variations in echinoderms. Ecological Monographs 79: 3-24, http://x.doi.org $10.1890 / 07-2136.1$

Vogler C, Benzie J, Lessios H, Barber P, Wörheide G (2008) A threat to coral reefs multiplied? Four species of crown-of-thorn starfish. Biology Letters 4: 696-699, http://dx.doi.org/10.1098/rsbl. 2008.0454

Walbran PD, Henderson RA, Jull AJT, Head MJ (1992) Evidence from sediments of long-term Acanthaster planci predation on corals of the Great Barrier Reef. Science 245: 847-850, http://dx.doi.org/10.1126/science.245.4920.847

Willan RC, Russell BC, Murfet NB, Moore KL, Mcennulty FR, Horner SK, Hewitt CL, Dally GM, Campbell ML, Bourke ST (2000) Outbreak of Mytilopsis sallei (Recluz, 1849) (Bivalvia: Dreissenidae) in Australia. Molluscan Research 20: 25-30, http://dx.doi.org/10.1080/13235818.2000.10673730

Young TP (2000) Restoration ecology and conservation biology. Biological Conservation 92: 73-83, http://dx.doi.org/10.1016/S00063207(99)00057-9

Youssef M, Kooij R, Scoglio C (2011) Viral conductance: Quantifying the robustness of networks with respect to spread of epidemics. Journal of Computational Science 2: 286-298, http://dx.doi.org/10.1016/j.jocs.2011.03.001 